\title{
Integration of Processes in the Study of Insight and Innovation
}

\author{
Thea Ionescu*, Alexandra Marian, Paula Moldovan, Beatrix Perde, Roxana Vescan, \\ Calin Hopsitar, Doris Rogobete, \& Ligia Suciu \\ Developmental Psychology Lab, \\ Department of Psychology, \\ Babeş-Bolyai University, Romania \\ ${ }^{*}$ Corresponding author theaionescu@psychology.ro
}

Received 14 April 2017; accepted 26 September 2017; published 21 November 2017.

\begin{abstract}
Humans are known to be able to solve problems creatively, but how exactly this occurs is still a matter of debate. Insight problem solving is one important way to study creativity in adults, but studies that use this method with preschool children are rare. In this paper, we present two studies: one in which the problem is solved with known objects (participants were preschool children aged 4 to 7 years) and one in which new objects were created (participants were children aged 5 to 6 years and adults). For both studies, results are discussed in relation to the various processes that can explain insight problem solving. We argue that the integration of these processes under the overarching variability-stability-flexibility pattern might be a better way to investigate insight and ultimately to understand innovation.
\end{abstract}

Keywords: innovation; insight; novelty.

\section{Introduction}

Insight is a highly praised phenomenon when it comes to discussing creativity and innovation. Whenever one is faced with an intriguing problem, an insightful moment is thought to bring the solution all of a sudden; it is the spontaneous manifestation of a problem's solution in conscious thought (Hélie \& Sun, 2010). The study of insight was introduced in modern psychology by gestalt psychologists, for whom the insight phenomenon was a perceptual and conceptual reorganization and a sudden transformation of how one sees a problem (Klein \& Jarosz, 2011; Ormerod, MacGregor, \& Chronicle, 2002). Recent research suggests that insight and creative thoughts make a 
decisive contribution to innovation that represents the materialization of the creative process in artifacts capable of inducing change at the societal level (Carr, Kendall, \& Flynn, 2016; Gummerum \& Denham, 2014). As such, understanding the workings of insight is fundamental to elucidate the processes of creativity and innovation.

Deeply connected to insight is functional fixedness, which represents the fact that the problem solver will encounter difficulties in finding appropriate new uses for a certain object because of previous knowledge of its use (Adamson \& Taylor, 1954; Yonge, 1966). An interesting phenomenon that caught the attention of researchers was the discrepancy between children aged 6, who show functional fixedness, and children aged 5, who are not subject to this effect (see Defeyter \& German, 2003; German \& Defeyter, 2000). German and Defeyter (2000) argue that compared to adults, younger children have wider criteria of what can count as an object's function. More specifically, any intentional use can be its function. The authors interpret this as going from flexible thinking, to rigid thinking, and then back to being flexible during early development. As this remains an understudied issue, we set out to investigate the development of insight problem solving, particularly because we were puzzled by children's progression from flexible thinking to rigidity and then back to flexibility. To this end, we analyzed insight problem solving both with known objects and problems from the literature, and with new objects and problems created in the lab.

The paper is structured as follows: first, we briefly present the two lines of investigation in two studies and their results. The second line of investigation requires further examination before its final objective is achieved, but we present insights from the pilot data that speak for differences between children and adults when it comes to considering what new objects are. Importantly, we will show that integrating children's and adults' behaviors when solving new problems under the variabilitystability-flexibility pattern (Ionescu, 2017) may lead to a more coherent picture about the development of creativity. We will end the paper with a discussion of some implications and future directions for this research.

\section{Insight Problem Solving with Known and New Objects}

We investigated the way children aged 4 to 7 years solve insight problems for two reasons: first, to investigate younger children to see whether they show the same lack of functional fixedness as 5-year-old children; second, to analyze multiple dependent measures, and not only whether they choose the target object first, as is shown in the current literature. In our first study, we created an insight problem with familiar objects based on the one used by Defeyter and German (2003; e.g., a clear plastic cup and a straw-see Appendix A). The sample of participants consisted of sixty-seven children, divided into 3 age groups: 4-5 years old, 5-6 years old and 6-7 years old. There were two conditions: the experimental group, in which the experimenter 
demonstrated the functions of the target objects (e.g., drank with the straw) and the control group, in which the objects were simply placed in front of the children. Participants were scored for the first selected object, the latency before the target object was selected, and the problem-solving behavior (whether they solved the problem with the target object, with another object, or did not solve it).

The results show that regarding the selection of the target object as the first object, the participants' performance increased with age: in the experimental group, $16.7 \%$ (4-5 years), 27.3\% (5-6 years) and 41.2\% (6-7 years), and in the control group, $50 \%$ (4-5 years), 63.6\% (5-6 years) and $87.5 \%$ (6-7 years). We found significant differences in the group of 6- and 7-year-olds between the two conditions which indicate the functional fixedness as reported in Defeyter and German (2003). Still, as the visual inspection shows, children's performance improves in both conditions as they get older; when we tested for the effect of age in the experimental condition, we found none. The latency from the time when the experimenter finished presenting the problem until the target object was selected showed that the children in the 6-7 years old group were faster than the other two age groups. So, how could it be that older children are better (and faster) than the other two groups at selecting the target object, yet also show functional fixedness?

Our second study aimed to analyze the role of set-shifting and knowledge in creative problem solving and to show that flexibility is more than just switching between perspectives (Ionescu, 2012). To this end, we created a new set of objects and piloted them on seven adults (second year undergraduate students) and on twenty-nine children aged 5 to 6 years old. They were presented one by one with the 6 new objects (e.g., five glued wooden blocks, a bent wire-see Appendix B) and were asked what they thought each object was.

Analysis of the answers to this question shows that $76.1 \%$ of adults gave answers based almost strictly on the form of the objects, while only $55 \%$ of the children did so. Also, while only $11.9 \%$ of the adults offered answers unrelated to the form of the objects, $27.5 \%$ of the children did so. While adults gave more exact descriptions of what the objects were (e.g., glued wooden blocks for the blocks), children gave more interesting answers, both when they answered based on form (e.g., a tangled shape for the bent wire) and when the answers were not strictly related to the form (e.g., musical instrument, alien or metal detector for the bent wire). We observed the opposite when we piloted the newly created names for the objects (e.g., Aki, Cona): while children were willing to say different things about what the objects were, with the names they were very cautious, with $74.7 \%$ of them choosing "I don't know" as an answer. Adults, on the other hand, tended to transform the words so that they become meaningful words in Romanian (e.g., "aici" meaning "here" for Aki or "con" meaning "cone" for Cona). 
The results of these two studies can be read from multiple perspectives or, technically speaking, based on the different processes involved. First, we might interpret them using the concept of "creativity 1" (Glăveanu, 2011), or, more specifically, the idea that children are more willing to play with ideas and generate them freely. This is best seen in the results of study 2, in which children went further from the exact shape of the objects that were shown to them than adults did. Moreover, in study 1 this can be inferred from children's willingness to try different objects until the problem is solved. Also relevant here is that the 6-year-olds were capable of overcoming the mental rut (i.e., the impasse caused by the repeated exploration of knowledge elements in the unsuccessful search for solutions that activate incorrect pathways; Defeyter \& German, 2003); they solved the problem even if they did not use the target object.

Furthermore, at younger ages, children generate ideas without tying them to a specific purpose. This idea can lead us to a second interpretation of the present results; namely, to goal orientation. In other words, at older ages children have already started to understand that certain problems require solutions with specific characteristics (Magid, Sheskin, \& Schulz, 2015). This could show that children start grasping the idea of goals and searching for answers that fit the characteristics of the problem; this is shown by the 6-7 years old children in Study 1, who either solved the problem with the target object or with one that resembled the characteristics of the target object.

A third reading implicates inhibitory control. Developmental studies have shown that preschoolers are in a period when inhibition develops greatly (Carlson \& Moses, 2001). Children's performance at solving problems with known objects in study 1 increased with age, corresponding to the developmental pattern of inhibitory control. At 6-7 years of age, children are already better at suppressing irrelevant information and using that which is relevant to make their choices more goal-oriented in problem solving. In contrast, younger children fail to do so, as suggested by the fact that they either try all objects until they find the right one or they fail to solve the problem altogether. Regarding the second study, children seemed to show lower inhibition when dealing with new objects, and better inhibition when dealing with new words, while in adults the pattern was reversed. We will return to this issue in the next section.

The differences between children and adults with unknown objects can also be explained by referring to pretend/symbolic play as the fourth interpretation. Symbolic play reaches its peak at 3-5 years of age and then decreases (Bergen, 2002). Children tend to suggest more uses for an object if they have engaged with it in play beforehand (Dansky, 1980). Pellegrini (1984) explained this phenomenon as a result of the exploration mindset that is favored in play situations, when children build wider associations for objects based on their features. Given that children engage in pretend play more often than adults, it is likely that this activity makes it easier for children to connect the 'what it is' of an object to 'what it can become'. Our second study showed that, as compared to adults, children gave more unusual answers for new 
objects. This finding may be closely related to imagination, which provides the individual with the chance to infer a richer set of links between the elements of the situation/object/problem (Magid et al., 2015).

Finally, we can read our results through the lens of the educational environment; more specifically, the types of activities children are engaged in at this age. Preschool children play a lot with objects in different ways, but they do not yet play as much with language as literacy develops during early school years (Cain, 2010). As a consequence, we observed that children were willing to give more unrelated meanings to objects, while they did not "play" with words. In contrast, adults relied on their linguistic experience and rich vocabulary to offer answers closely related to the form of the words.

\section{Integration of Processes and the Study of Insight and Innovation}

Because every mechanism presented above is oftentimes explained via other mechanisms (e.g., play and imagination), and because sometimes concepts seem to actually be in opposition (e.g., "playful set" as leading to creativity [Clark et al., 1989], and "mental set" or "the continued attempt to use a previously successful method in problems where the method is no longer adequate" as leading to perseveration [Adamson \& Taylor, 1954, p. 122]), we believe that an integrative approach is better suited to describing the phenomenon of insight and to serve as a guide for a new research agenda. For instance, we can see that in order to find a solution to a problem, children progress from a spontaneous, explorative approach to a more deliberate, controlled attitude. This process might be necessary to reach an optimum balance between the two processing modes (Mok, 2014) that can enable them to find a creative solution to a problem. The spontaneous approach young children take might be aided by processes such as imagination or pretend play, which are also interrelated. Imagination can be seen as a cognitive mechanism for efficiently generating new ideas without necessarily assessing their truth (Magid et al., 2015) and could be aided by the broad associations children make during pretend play, when they are in the exploration mindset (Pellegrini, 1984). Defined like this, the process closely resembles creativity 1 , or the playfulness of coming up with new ideas (Glăveanu, 2011). As they grow up, children's inhibition and goal understanding develop, thus supporting a more deliberate attitude in problem solving. We therefore propose that going up one level and analyzing the more general states we are in when solving creative problems may lead us to a more accurate description of what is going on. More specifically, we refer to the state of variability (when a cognitive system tries out any response in order to solve a problem), the state of stability (when the system knows the answer and uses it when needed), and the state of flexibility (when the system goes beyond the known answer, explores new avenues, and solves a difficult problem; Ionescu, 2017). 
For instance, we can speculate that in study 1, younger children manifest variability when solving a problem, whereas older children show both stability and variability when they approach the same problem. So, what is believed to be functional fixedness in older children (see Defeyter \& German, 2003; German \& Defeyter, 2000) could actually be stability (Ionescu, 2017). Younger children undergo a process of trial and error when solving insight problems: this can be seen in their tendency to try out several objects and can be considered a variability state; older children-even if they also try-are more influenced by the demonstrated function and therefore show stability. In study 2 , we can also ascribe variability to children's behavior with new objects and stability to adults; when it comes to words, we can speculate that adults show flexibility and children stability.

These states include a wide range of cognitive mechanisms (and not only cognitive; Ionescu, 2012) that continuously interact, as explained above. Moreover, some mechanisms can function efficiently and inefficiently at the same age. One such example is inhibition, which seems to be low in the case of objects and high in the case of words in children in our second study. This points to an interesting question: Do preschool children have low or good inhibitory abilities? The literature points to low inhibition in general at this age (Kerns \& Muller, 2015), but we see that with words they are very cautious, and as such, may be displaying rather good inhibition. We believe that integrating the processes into this larger pattern of going from variability to stability and then to flexibility might help us clarify how certain mechanisms develop and interact in order to allow us to become creative.

\section{Implications, Future Directions, and Concluding Remarks}

Although we know that several processes are important for insight and innovation, we do not yet know how these processes interact in order to arrive at a product that is later called innovative. Looking at this problem via the variability-stabilityflexibility pattern could lead us to understand the dynamics of interrelations between different cognitive processes. It could also lead to a better understanding of the flow between these very patterns: they might follow one after another linearly, but might also be incorporated into each other, so that passing from one state to another becomes more fuzzy and nonlinear (Ionescu, 2017). Moreover, by analyzing the passage from one state to another, we might better understand how each state is needed to get to the next one. In other words, maybe we do not need to overcome functional fixedness or stability, but instead need to understand how to utilize this state in order to achieve flexibility. Moreover, looking at insight problem solving through the lenses of this pattern might help us clarify what certain processes are. There is little agreement in the current literature with regard to concepts such as creativity (Simonton, 2016) or flexibility (Ionescu, 2012, 2017); as seen above, even some apparently precisely circumscribed mechanisms are not very clear upon closer inspection (e.g., inhibition during preschool years). 
How to further study the proposed approach? A microgenetic study might be well suited to observing the workings of the cognitive system over a brief period of great change (Siegler, 1999). More specifically, over 3 weeks of repeated testing, one could manipulate the aforementioned processes in pairs in different combinations to see which combination is essential for insight to appear. For example, several groups of preschoolers could be involved either in pretend play and games that involve inhibition, or in imaginative scenarios and goal-setting games; their performance in insight problem solving could then be evaluated. Also, the group of children could be split into two subgroups, one that shows variability and one that shows stability, and again their progression to flexibility would be assessed.

In conclusion, we believe that studying these processes together can lead to a more accurate picture of how the system functions when solving problems in a creative way. Even if it might seem difficult at first to put these ideas into rigorous experiments, "the challenge for our field is to prove it," as Russ \& Wallace nicely assert (2013, p. 146).

\section{References}

Adamson, R. E., \& Taylor, D. W. (1954). Functional fixedness as related to elapsed time and to set. Journal of Experimental Psychology, 47(2), 122-126. doi:10.1037/h0057297

Ayman-Nolley, S. (1992). Vygotsky's perspective on the development of imagination and creativity. Creativity Research Journal, 5(1), 77-85, doi:10.1080/10400419209534424

Beck, S. R., Williams, C., Cutting, N., Apperly, I. A., \& Chappell, J. (2016). Individual differences in children's innovative problem-solving are not predicted by divergent thinking or executive functions. Philosophical Transactions of the Royal Society B: Biological Sciences, 371(1690), 1-11. doi:10.1098/rstb.2015.0190

Bergen, D. (2002). The role of pretend play in children's cognitive development. Early Childhood Research \& Practice, 4(1). Retrieved from http://ecrp.uiuc.edu/v4n1/bergen.html

Cain, K. (2010). Reading development and difficulties: An introduction, Oxford, UK: Wiley-Blackwell.

Carlson, S. M., \& Moses, L. J. (2001). Individual differences in inhibitory control and children's theory of mind. Child Development, 72(4), 1032-1053. doi:10.1111/1467-8624.00333

Carr, K., Kendal, R. L., \& Flynn, E. G. (2016). Eureka! What is innovation, how does it develop, and who does it? Child Development, 87(5), 1505-1519. doi:10.1111/cdev.12549

Clark, P. M., Griffing, P. S., \& Johnson, L. G. (1989). Symbolic play and ideational fluency as aspects of the evolving divergent cognitive style in young children. Early Child Development and Care, 51(1), 77-88, doi:10.1080/0300443890510107

Dansky, J. L. (1980). Make-believe: A mediator of the relationship between play and associative fluency. Child Development, 51(2), 576-579. doi:10.2307/1129296 
Defeyter, M. A., \& German, T. P. (2003). Acquiring an understanding of design: Evidence from children's insight problem solving. Cognition, 89(2), 133-155. doi:10.1016/S00100277(03)00098-2

German, T. P., \& Defeyter, M. A. (2000). Immunity to functional fixedness in young children. Psychonomic Bulletin \& Review, 7(4), 707-712.

German, T. P., \& Johnson, S. C. (2002). Function and the origins of the design stance. Journal of Cognition and Development, 3(3), 279-300. doi:10.1207/S15327647JCD0303_2

Glăveanu, V. P. (2010). Paradigms in the study of creativity: Introducing the perspective of cultural psychology. New Ideas in Psychology, 28(1), 79-93. doi:10.1016/j.newideapsych.2009.07.007

Glăveanu, V. P. (2011). Children and creativity: A most (un)likely pair? Thinking Skills and Creativity, 6(2), 122-131. doi:10.1016/j.tsc.2011.03.002

Gummerum, M., Denham, S. L. (2014). Cognitive innovation: From cell to society. Europe's Journal of Psychology, 10(4), 586-588. doi:10.5964/ejop.v10i4.879

Hélie, S., \& Sun, R. (2010). Incubation, insight, and creative problem solving: A unified theory and a connectionist model. Psychological Review, 117(3), 994-1024. doi:10.1037/a0019532

Ionescu, T. (2012). Exploring the nature of cognitive flexibility. New Ideas in Psychology, 30(2), 190-200. doi:10.1016/j.newideapsych.2011.11.001

Ionescu, T. (2017). The variability-stability-flexibility pattern: A possible key to understanding the flexibility of the human mind. Review of General Psychology, 21(2), 123-131. doi:10.1037/gpr0000110

Kemple, K. M., \& Nissenberg, S. A. (2000). Nurturing creativity in early childhood education: Families are part of it. Early Childhood Education Journal, 28(1), 67-71.

Klein, G., \& Jarosz, A. (2011). A naturalistic study of insight. Journal of Cognitive Engineering and Decision Making, 5(4), 335-351. doi:10.1177/1555343411427013

Lane, J. D., Ronfard, S., Francioli, S. P., \& Harris, P. L. (2016). Children's imagination and belief: Prone to flights of fancy or grounded in reality? Cognition, 152, 127-140. doi:10.1016/j.cognition.2016.03.022

Lillard, A. S., Lerner, M. D., Hopkins, E. J., Dore, R. A., Smith, E. D., \& Palmquist, C. M. (2012). The impact of pretend play on children's development: A review of the evidence. Psychological Bulletin, 139(1), 1-34. doi:10.1037/a0029321

Magid, R. W., Sheskin, M., \& Schulz, L. E. (2015). Imagination and the generation of new ideas. Cognitive Development, 34, 99-110. doi:10.1016/j.cogdev.2014.12.008

Mok, L. W. (2014). The interplay between spontaneous and controlled processing in creative cognition. Frontiers in Human Neuroscience, 8. doi:10.3389/fnhum.2014.00663

Morasch, K. C., \& Bell, M. A. (2011). The role of inhibitory control in behavioral and physiological expressions of toddler executive function. Journal of Experimental Child Psychology, 108(3), 593-606, doi:10.1016/j.jecp.2010.07.003 
Müller, U., \& Kerns, K. (2015). The development of executive function. In L. S. Liben \& U. Müller (Vol. Eds.), R. M. Lerner (Series Ed.), Handbook of child psychology and developmental science: Cognitive processes (7th ed., pp. 571-623). Hoboken, NJ: John Wiley. doi:10.1002/9781118963418.childpsy214

Nowak-Fabrykowski, K. (1994). Can symbolic play prepare children for their future? Early Child Development and Care, 102(1), 63-69, doi:10.1080/0300443941020104

Ormerod, T. C., MacGregor, J. N., \& Chronicle, E. P. (2002). Dynamics and constraints in insight problem solving. Journal of Experimental Psychology: Learning, Memory, and Cognition, 28(4), 791-799. doi:10.1037//0278-7393.28.4.791

Pellegrini, A. D. (1984). The effects of exploration and play on young children's associative fluency. Imagination, Cognition and Personality, 4(1), 29-40. doi:10.2190/0W5N-X8E8WKWF-9A1R

Reuland, E. (2016). Language and imagination: Evolutionary explorations. Neuroscience \& Biobehavioral Reviews, 1-24, Advance online publication. doi:10.1016/j.neubiorev.2016.12.017

Russ, S. W., \& Wallace, C. E. (2013). Pretend play and creative processes. American Journal of Play, 6(1), 136-148.

Schachar, R., \& Logan, G. D. (1990). Impulsivity and inhibitory control in normal development and childhood psychopathology. Developmental Psychology, 26(5), 710-720.

Siegler, R. S. (1999). Strategic development. Trends in Cognitive Sciences, 3(11), 430-435. doi:10.1016/S1364-6613(99)01372-8

Simonton, D. K. (2016). Creativity, automaticity, irrationality, fortuity, fantasy, and other contingencies: An eightfold response typology. Review of General Psychology, 20(2), 194-204. doi:10.1037/gpr0000075

Williams, B. R., Ponesse, J. S., Schachar, R. J., Logan, G. D., \& Tannock, R. (1999). Development of inhibitory control across the life span. Developmental Psychology, 35(1), 205-213.

Yonge, G. D. (1966). Structure of experience and functional fixedness. Journal of Educational Psychology, 57(2), 115-120. doi:10.1037/h0022967 


\section{Appendices}

Examples of objects from Study 1 (A) and Study 2 (B).

A.

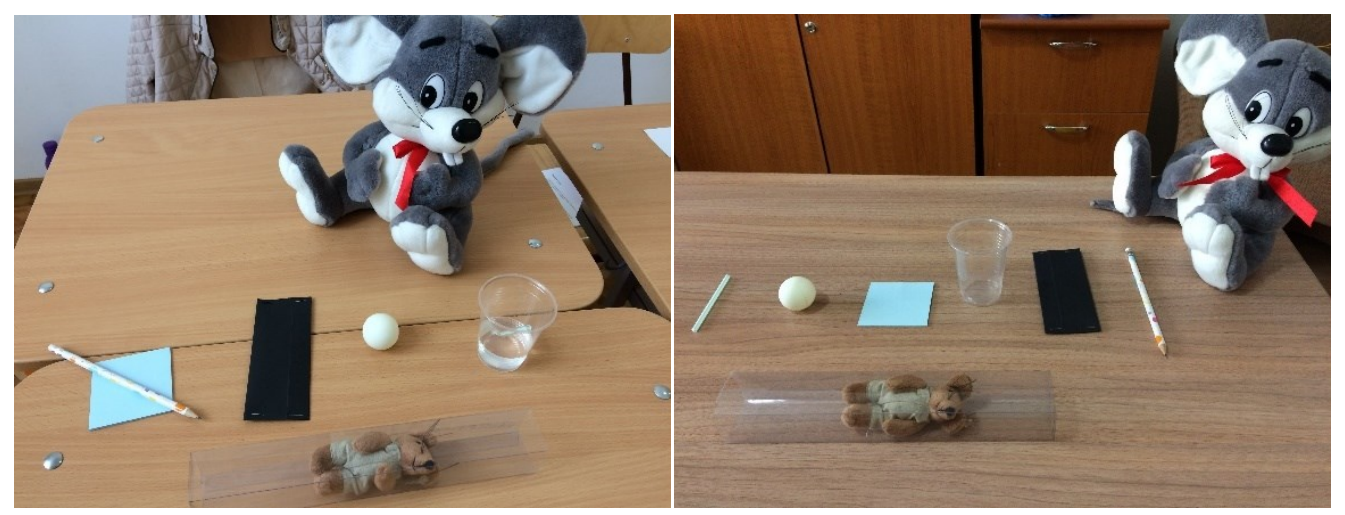

B.

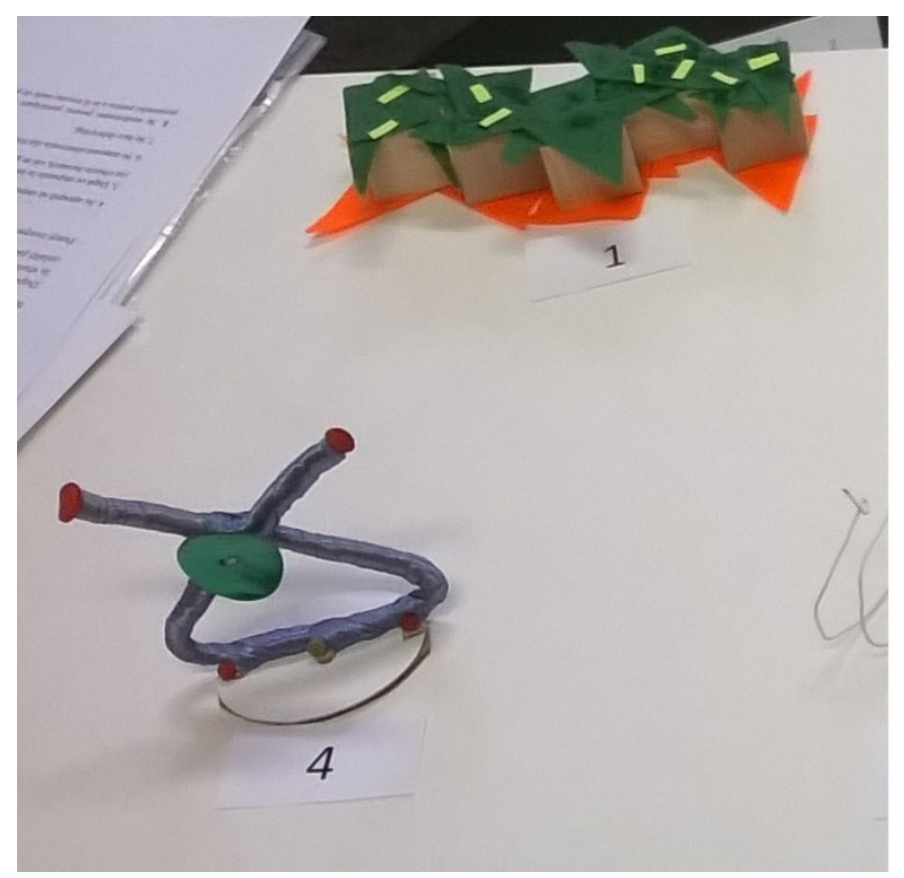




\section{First response to "Integration of Processes in the Study of Insight and Innova- tion" by Vaibhav Tyagi}

This well-presented paper is a reminder that creativity is a complex phenomenon. In his paper entitled The cognitive neuroscience of creativity, Dietrich (2004) discussed at least two modes of processing underlying creativity: Spontaneous and Deliberate. This paper discusses the former: Spontaneous creativity in the context of a relatively well-studied phenomenon, Insight and creative problem solving. On the other hand, deliberate creativity can be exemplified through a process of trial and error. For instance, the Mona Lisa was not created in an instance of Insight, instead it took years to finish and allegedly was never complete as envisioned by its creator. Thus, it could be argued that the process of its creation was relatively deliberate. The current paper is a great read and can be supplemented by Dietrich's views to obtain a well-rounded understanding of the process of creativity.

Aside from the question of what creativity really is, another question that has haunted the field of creativity for decades is how to best investigate it. Researchers such as Vlad Glăveanu and others have suggested three, four and five P frameworks of creativity. In short, creativity can be studied through the process of being creative, through the products that are being created, or even through the person who is creating them. This paper generates interest in the creative process and creative products. For additional reading on the creative person, Mark Runco's work (2014) can often prove quite useful.

Finally, there is the question of who can be creative. Researchers have long debated whether animals can be creative, or-a question more relevant to this discussioncan children be creative? Without explicitly going into this debate, the current paper takes a clear stand on investigating creativity in children. However, it might be worth situating the present work in the light of this debate through the works of other researchers. This becomes especially important since, in Dietrich's framework, the mode of processing in children is somewhat limited to spontaneous creativity.

Overall, this short paper is successful at presenting this interesting topic to a wider range of audience.

\section{References}

Dietrich, A. (2004). The cognitive neuroscience of creativity. Psychonomic Bulletin \& Review, 11(6), 1011-1026. doi:10.3758/BF03196731

Runco, M. A. (2014). Creativity: Theories and themes: Research, development, and practice (2nd ed.). San Diego, CA: Elsevier. 


\section{Second response to "Integration of Processes in the Study of Insight and Inno- vation" by Judy Edworthy}

Upon reading this paper and noting its results (as a non-expert in this area), the two systems of the dual processing approach to cognition immediately come to mind (Kahneman, 2011; Paivio, 2014). The properties assigned to System 1 (such as unconscious reasoning, low effort, large capacity, nonverbal, contextualized, domainspecific) and, by contrast, System 2 (such as conscious reasoning, small capacity, language-based, abstract, domain-general) seem to cut across the tasks and the results obtained, and thus might provide a further perspective in looking at the variabilitystability-flexibility question. In the sense of Haeckel's statement that ontogeny recapitulates phylogeny-a belief/understanding that the development of an individual from birth to adulthood (ontogeny) expresses all the intermediate forms of the species (phylogeny) - we might expect children to demonstrate more aspects of System 1, the old system, than System 2, but for this balance to change as they reach adulthood.

Of course, not everyone agrees with Haeckel, or even with the dual-process theory. One might prefer the dynamic graded continuum (DGC) approach (Cleeremans \& Jiménez, 2002), or the fuzzy trace theory (Reyna \& Brainerd, 1995) with its distinction between the verbatim and gist memory systems, which also seem appropriate here, as it shows that we rely more on gist than verbatim information as we become older.

\section{References}

Cleeremans, A., \& Jiménez, L. (2002). Implicit learning and consciousness: A graded, dynamic perspective. In R. M. French \& A. Cleeremans (Eds.), Implicit learning and consciousness (pp. 1-40). Hove, UK: Psychology Press.

Kahneman, D. (2011). Thinking, fast and slow. New York, NY: Farrar, Straus \& Giroux.

Paivio, A. (2014). Mind and its evolution: A dual coding theoretical approach. New York, NY: Psychology Press.

Reyna, V. F., \& Brainerd, C. J. (Eds.) (1995). Fuzzy-trace theory: An interim synthesis. Learning and Individual Differences, 7(2), 1-75. doi:10.1016/1041-6080(95)90031-4 


\section{Third response to "Integration of Processes in the Study of Insight and Inno- vation" by Chun-Wei Hsu}

I like the idea of using the variability-stability-flexibility pattern to approach insight and innovation as it can explain more about how we use different cognitive abilities to be creative when doing insight problem solving in different stages of life and how we integrate these processes.

Several cognitive functions are mentioned in the article, including goal direction and inhibitory control. Here, I propose that "attention" may also play a critical role in generating ideas as a certain attentional span is required to solve a problem creatively and the relationship between attention persistence and creativity has been investigated in previous literature. Zabelina and Beeman (2013) examined this relationship by implementing an attention-switching task in which participants had to identify whether the stimulus contained the letters S or H within hierarchically constructed letters (e.g., a large S made up of small Es-global level; a large E made up of small Ss-local level). On the other hand, participants' creative cognition was measured by a self-report, creativity achievement questionnaire (CAQ) in which participants reported their level of achievement in 10 different fields, e.g., writing, visual arts, music, science, etc. They found that highly creative individuals showed higher levels of attentional persistence when they made more errors when switching the level of attention, even after controlling for general intelligence. Therefore, attention might be another important cognitive function in the development of creativity in children; it is still unknown how attention affects creative cognition in children.

Also, working memory, which is another executive function, is strongly related to performance in complex cognitive tasks. Working memory capacity is needed to solve insight problems. Have the authors considered this?

Finally, the authors mentioned that the variability-stability-flexibility pattern might follow one another linearly and might also be included in each other; thus, passing from one state to another becomes more fuzzy and nonlinear. Is it possible for this pattern to go backwards? For example, in study 2, compared to children, adults offered fewer answers that were unrelated to the form of the objects. The authors ascribed stability (i.e., when the system knows the answer and uses it when needed) to adults' behavior and variability (i.e., when a cognitive system tries out any response for solving the problem) to children's behavior with new objects. However, is it possible that children showed the state of flexibility (i.e., when the system goes beyond the known answer, explores new avenues) in this case, as preschool children play a lot with objects in different ways, therefore they can think beyond the known answer and explore a new avenue? On the other hand, the variability-stability-flexibility pattern might go backwards for adults' behavior since they do not play with objects as 
often as children. Thus, unfamiliarity with the objects makes them fix their function and the mental state for adults when solving an insight problem might become stability, even though they developed the state of flexibility at some point.

\section{Reference}

Zabelina, D. L., \& Beeman, M. (2013). Short-term attentional perseveration associated with reallife creative achievement. Frontiers in Psychology, 4, 1-8. doi:10.3389/fpsyg.2013.00191 